\title{
Fuzzy MCDM Model for Risk Factor Selection in Construction Projects
}

\author{
Pejman Rezakhani \\ Department of Architecture and Civil Engineering, Kyungpook National University \\ 1370 Sangyeok-dong, Buk-gu, Daegu, 702-701, Korea \\ E-mail: rezakhani@knu.ac.kr
}

\begin{abstract}
A risk is defined as the potential for complications and problems with respect to the completion of a project and the achievement of a project goal. The development of a systematic risk management plan is important for successful project delivery. Risk factor identification and selection is the first step in risk management plan that determines which risk components may adversely affect the project objectives. Due to the unique properties of construction operations, many risk factors are involved in construction project and by an effective and systematic risk selection process the most critical risks can be distinguished to have more attention. In this paper through a comprehensive literature survey, most significant risk factors in a construction project are classified in a hierarchical structure. For an effective risk factor selection, a modified rational multi criteria decision making model (MCDM) is developed. This model is a consensus rule based model and has the optimization property of rational models. By applying fuzzy logic to this model, uncertainty factors in group decision making such as experts influence weights, their preference and judgment for risk selection criteria will be assessed. Also an intelligent checking process to check the logical consistency of experts` preferences will be implemented during the decision making process. The solution inferred from this method is in the highest degree of acceptance of group members. Also consistency of individual preferences is checked by some inference rules. This is an efficient and effective approach to prioritize and select risks based on decisions made by group of experts in construction projects. The applicability of presented method is assessed through a case study.
\end{abstract}

Keywords: Multi criteria decision making, risk management, fuzzy set, construction management.

ENGINEERING JOURNAL Volume 16 Issue 5

Received 3 April 2012

Accepted 1 May 2012

Published 1 October 2012

Online at http://www.engj.org/

DOI:10.4186/ej.2012.16.5.79 


\section{Introduction}

The development of a systematic risk selection plan is important for successful project risk management. The complexity of construction projects (i.e., subways, skyscrapers, and highways, etc) have been increased due to the demanding of more advanced structures and infrastructures. The complexity introduces more uncertain factors into project management. These factors should be identified and controlled to deliver a project successfully. There is a difference between delivering a successful project and project management success. The essential measure of a successful project is that it delivered a successful outcome to the business. This is largely the responsibility of the project sponsor. Project Management success on the other hand is delivering a project to the agreed Scope, Time, Cost and Quality, while maintaining a customer relationship. This is largely the responsibility of the project manager and decisions which he makes in lifecycle of the project.

An efficient risk selection methodology that is a part of decision making process involved in risk should handle the uncertain factors which may lead to a failure in project objective and provide a guide map to mitigate them. In order to understand the art of good risk selection, one must be able to identify the different types of risks associated with each decision. Risks can come from uncertainty in financial markets, project failures, legal liabilities, credit risk, time risk, human risk, accidents, natural causes and disasters as well as deliberate attacks from an adversary. Effective risk selection methodology reduces the opportunity for finances to be used fruitlessly, making sure that all resources are utilized efficiently while minimizing the potential for injury to employees. It is therefore essential to develop new risk selection method to identify and assess construction risks in which has no limitation in risk factor input, easy to element modification, programmable, has a unique risk factor assessment and any risk information produced is processed and reliably applied to decision making process.

Risk classification is an important step in the risk selection process, as it attempts to structure the diverse risks that may affect a project. In this study through a comprehensive literature survey of different risk classification approaches, most effective risk factors in a construction project are classified by their source and effect on project objective. Although this classification is comprehensive but it is not restricted and depending on different situations of a project, some new factors can be added to this classification. To make the risk management plan as effective as possible, the most effective risk factors on project objectives should be prioritized and selected through group decision making. Group members consist of different experts in construction industry with variety in experience, knowledge and expertise. In this research we proposed a fuzzy multi- criteria group decision making solution which is based on the Hybrid RationalPolitical model. The proposed model has ten steps within three stages. The rest of the paper is organized as follows. In the next section, a literature survey on different methods of risk classification with focus on construction project risks is introduced. This section ends with a suggested hierarchical risk factor classification in a construction project. Then in the subsequent section, the proposed methodology for risk factor prioritization and selection in defined. Applicability of proposed model is assessed through a case study in next section and final section concludes the article.

\section{Risk Classification}

[1] defines risk classification as a provider of a structure that ensures a comprehensive process of systematically identifying risks to a consistent level of detail and contributes to the effectiveness and quality of the identify risks process. Risk classification is an important step in the risk assessment process, as it attempts to structure the diverse risks that may affect a project. Construction risks are classified in many ways by risk types (i.e., natures, and magnitudes, etc), the sources and/or origins, or project phase [2, 3, 4]).

[5] gave an extensive list of factors assembled from several sources, and classified in terms of risks retainable by contractors, consultants and clients. [6] classified construction risks into three groups, i.e. construction finance, construction time and construction design. [7] identified eight major risks accounting for project delay and ranked them based on a questionnaire survey with industry practitioners. [8] classified project risks by using the hierarchical risk breakdown structure (HRBS) and classified them into internal and external risks. [9] grouped risks into four subsets: environment, industry, client and project. [10] categorized them into six groups in accordance with the nature of the risks, i.e. financial, legal, management, market, policy and political. [11] proposed 15 risks concern with project cost and divided them into three groups: resource factors, management factors and parent factors. [12] mentioned the risk factors as the 
delay factors in construction projects. [13] used influence diagrams to define the factors which have influence on project risks. [14] classified risk factors as human, site, material and equipment factors. Based on the above literature review, we propose following risk classification.

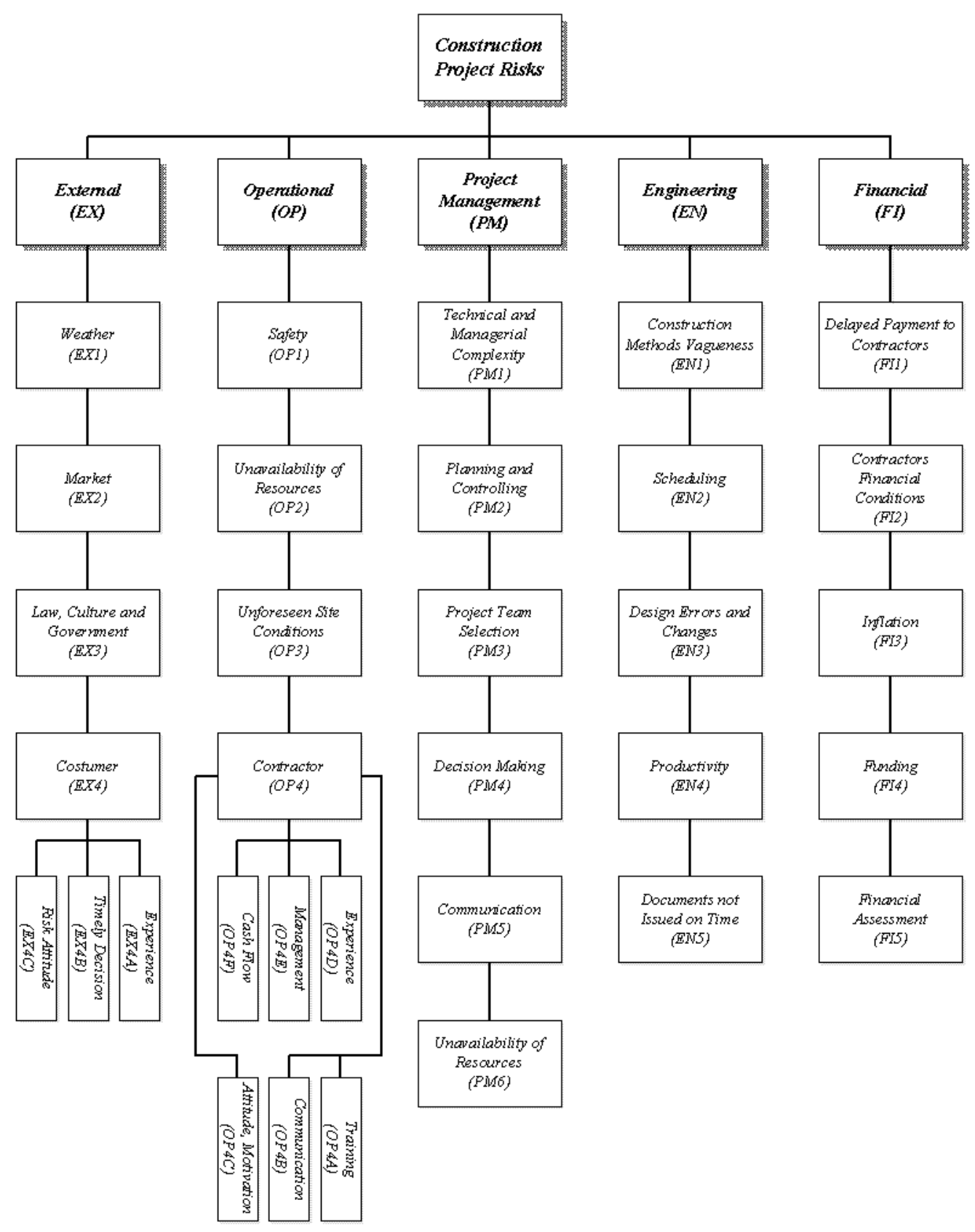

Fig. 1. Construction risk classification.

In proposed classification, risk factors are divided into five main categories and relative subcategories. Each risk factor is defined with an abbreviation to ease the selection process and the more important risk factors are put in the top of hierarchy. Although this classification covers the most associated risks in a construction projects but it can be modified considering the dominant conditions in projects.

\section{Risk Factor Prioritization and Selection}

After classifying the inherent risks in construction projects, it is very important to select and prioritize the risk items in order to have an efficient risk management plan. Many risk selection and assessment techniques currently used in construction industry are comparatively mature such as Fault Tree Analysis, 
Event Tree Analysis, Monte Carlo Analysis, Scenario Planning, Sensitivity Analysis, Failure Mode and Effects Analysis and Program Evaluation and Review Technique. These approaches are theoretically well established. However, they are confined in practicality because they need incorporating many factors and theirs weights, tedious calculations, and special mathematical knowledge and high quality data. Such data are hard to obtain or even have not existed in construction industry. Moreover, they are difficult to address the uncertainties and subjectivities associated with construction activities [14].

The construction projects are complex projects that involves with many participants. Therefore there are several risks occurred in any stage within construction projects those may not be evaluated by human or traditional methods. Since we have a finite number of criteria (project objectives which the effect of risk factors on them should be evaluated) and infinite number of feasible alternatives (associated risk factors which should be selected and prioritized), the multiple criteria decision making model is the best choice. The main factors that taken into consideration in mentioned model are decision makers influence weights, their preferences for risk factor selection and the criteria for assessing risks. Group members consist of different experts in construction industry with variety in experience, knowledge and expertise. Experts with higher degree of competence should be assigned higher weights. Experts may not know or consider all the relevant information for a decision problem. To conquer this subject, an uncertainty factor named preference of every decision maker and related belief matrices are considered.

To apply this model, risk factor classification, projects requirements and objectives should be determined. Experts select the risk factors and then rank them to select $\mathrm{N}$ of them. Risk assessment and ranking criteria will be nominated by group members and finally $\mathrm{T}$ criteria will be used. To incorporate human inconsistency in decisions, it is suggested that all group members corporate in group aggregation process to ensure that the disparate individuals come to share the same decision objectives. Any individual role in a decision process, a preference for alternatives, and a judgment for assessment criteria are often expressed by linguistic terms as normal, more important. To deal with these uncertain and vague terms, crisp mathematical approaches cannot be applied. To handle these uncertainties, inaccurate and vague linguistic terms, the fuzzy logic is applied. The theory of fuzzy sets provides a framework and offers a calculus to address these fuzzy statements.

\subsection{Methodology}

Let $P=\left\{P_{1}, P_{2}, \ldots, P_{n}\right\}, n \geq 2$ be a given number of experts in the decision making group to prioritize and select risks from classified risk factors. The proposed model has ten steps within three stages:

Stage 1: Risk factor, assessment criteria and experts' influence weights determination

Step 1: By proposing classified risks in a group, every expert may have one or several possible risk factor selection. Through discussions and summarizations, $S=\left\{S_{1}, S_{2}, \ldots, S_{m}\right\}, m \geq 2$ is selected from alternative pool as final risk factors (alternatives) for prioritization.

Step 2: A criterion pool is constructed in this step and every members ' assessment criteria is put into this pool. Each expert can propose his own assessment criteria for ranking and assessing the risk factors in this pool. Top T criteria, $C=\left\{C_{1}, C_{2}, \ldots, C_{t}\right\}$ are chosen as assessment criteria for risk selection problem.

Step 3: To consider the experience, knowledge and expertise of each expert, an influence weight is described and assigned to every expert. These influence weights are described by linguistic term $\tilde{v}_{k}, k=1,2, \ldots, n$.These weights can be determined through discussions in group or assigned by the leader of decision making group. These weights are assigned before or at the beginning of decision process. Table 1 shows related linguistic terms of decision makers. These linguistic terms and related membership functions are shown in Fig. 2. Triangular fuzzy numbers are used to map the linguistic terms to their corresponding fuzzy numbers. Table 2 presents a suggestive construction expert board to deal with risk selection in construction projects. 
Table 1. Linguistic terms for describing weights of decision makers.

\begin{tabular}{lcccc}
\hline Linguistic Terms & Membership Functions & Fuzzy Numbers & Intervals & Abbreviation \\
\hline \multirow{2}{*}{ Normal } & $5 \mathrm{x}$ & \multirow{2}{*}{$(0,0.2,0.4)$} & $0 \leq \mathrm{x} \leq 0.2$ & $\mathrm{c} 1$ \\
& $2-5 \mathrm{x}$ & & $0.2 \leq \mathrm{x} \leq 0.4$ & \\
Important & $5 \mathrm{x}-1$ & $(0.2,0.4,0.6)$ & $0.2 \leq \mathrm{x} \leq 0.4$ & $\mathrm{c} 2$ \\
\multirow{2}{*}{ More Important } & $3-5 \mathrm{x}$ & $0.4 \leq \mathrm{x} \leq 0.6$ & \\
& $5 \mathrm{x}-2$ & $(0.4,0.6,0.8)$ & $0.4 \leq \mathrm{x} \leq 0.6$ & $\mathrm{c} 3$ \\
\multirow{2}{*}{ Most Important } & $4-5 \mathrm{x}$ & & $0.6 \leq \mathrm{x} \leq 0.8$ & \\
& $5 \mathrm{x}-3$ & $(0.6,0.8,1)$ & $0.6 \leq \mathrm{x} \leq 0.8$ & \\
& $5-5 \mathrm{x}$ & $0.8 \leq \mathrm{x} \leq 1$ & $\mathrm{c}$ \\
\hline
\end{tabular}

Table 2. Suggestive construction expert board in decision group.

\begin{tabular}{lcr}
\hline Experts & Linguistic Terms & Abbreviation \\
\hline Construction Manager & Most Important & $\mathrm{c} 4$ \\
Senior Execution Engineer & More Important & $\mathrm{c} 3$ \\
Senior Design Engineer & More Important & $\mathrm{c} 3$ \\
Site Engineer with 15 Years Experience & Important & $\mathrm{c} 2$ \\
Expert Presented By Client & Normal & $\mathrm{c} 1$ \\
\hline
\end{tabular}

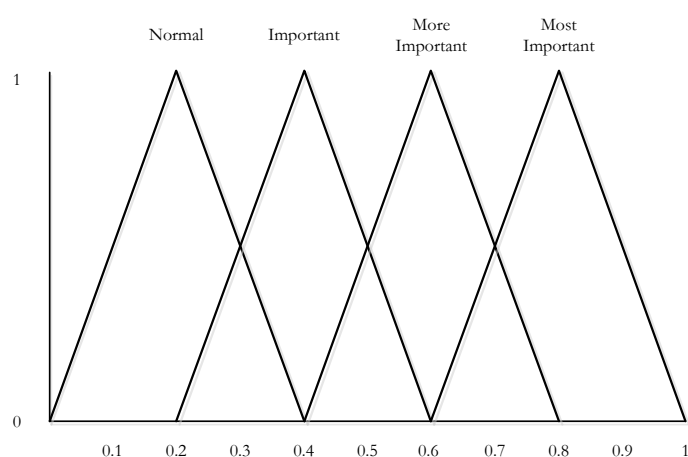

Fig. 2. M. F. of decision makers weights.

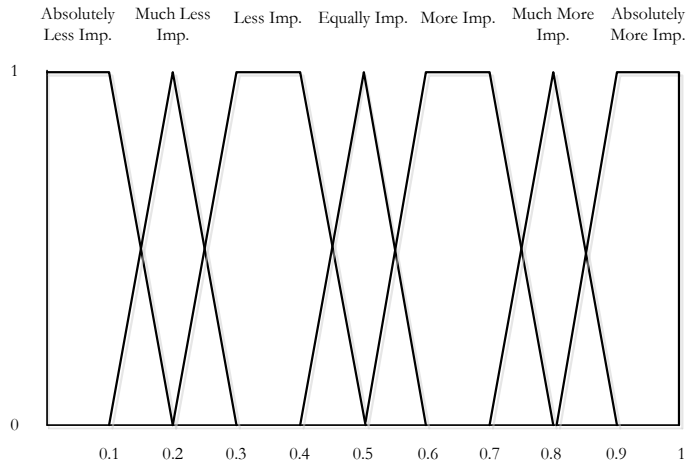

Fig. 3. M. F. of assessment criteria comparison.

Stage 2: Expert preference generation

In this step each expert by using a pair-wise comparison expresses his opinion about outcomes of step 2. At first, a pair-wise comparison matrix $E=\left[\tilde{e}_{i j}^{k}\right]_{t \times t}$ is established. Every member of this matrix represents the quantified judgments on pairs of assessment criteria $C_{i}$ and $C_{j}(i, j=1,2, \ldots, t, i \neq j)$. The linguistic terms and corresponding membership values which will be used for the comparison of the assessment criteria are described in Table 3 and Fig. 3. By utilizing the political model in this hybrid system, there is no obligation for experts to compare all the outcomes. Where ever the experts do not know or cannot compare the relative importance of assessment criteria $C_{i}$ and $C_{j}$ a ' $*$ ' sign will be placed in pairwise comparison matrix. By using following linguistic inference rules, the inconsistency of each pair-wise comparison matrix $E=\left[\tilde{e}_{i j}^{k}\right]_{t \times t}$ is corrected:

Rule 1: Positive-Transitive rule;

$$
\text { If } \tilde{e}_{i j}^{k}=a_{s}(s=4,5,6,7) \text { and } \tilde{e}_{j m}^{k}=a_{t}(t=4,5,6,7) \text {, then } \tilde{e}_{i m}^{k}=a_{\max (s, t)} \text {. }
$$


Rule 2: Negative-Transitive rule;

$$
\text { If } \tilde{e}_{i j}^{k}=a_{s}(s=3,2,1) \text { and } \tilde{e}_{j m}^{k}=a_{t}(t=3,2,1) \text {, then } \tilde{e}_{i m}^{k}=a_{\min (s, t)} \text {. }
$$

Rule 3: De-In-Uncertainty rule;

$$
\text { If } \tilde{e}_{i j}^{k}=a_{s}(s=4,5,6,7) \text { and } \tilde{e}_{j m}^{k}=a_{t}(t=3,2,1) \text { or }{ }^{\prime *} \text { ', then } \tilde{e}_{i m}^{k}=a_{i} \text { for any } t \leq i \leq \text { sor }^{\prime *}{ }^{\prime} \text {. }
$$

Rule 4: In-De-Uncertainty rule;

$$
\text { If } \tilde{e}_{i j}^{k}=a_{s}(s=3,2,1) o r^{\prime *}{ }^{\prime} \text {, and } \tilde{e}_{j m}^{k}=a_{t}(t=4,5,6,7) \text {, then } \tilde{e}_{i m}^{k}=a_{i} \text { for any } s \leq i \leq \text { tor }{ }^{\prime *}{ }^{\prime} \text {. }
$$

After calculating the comparison matrix $E=\left[\tilde{e}_{i j}^{k}\right]_{t \times t}$ by using the geometric mean of each row, consistent weights $w_{i}^{k}(i=1,2, \ldots, t)$ for every risk selection criterion is calculated. Resulting fuzzy numbers are normalized and described as $\tilde{w}_{i}^{k}=\frac{w_{i}^{k}}{\sum_{i=1}^{t} w_{i_{0}}^{k^{R}}}$ for $i=1,2, \ldots, t ; k=1,2, \ldots, n, \quad \tilde{w}_{i}^{k} \in F_{T}^{*}(\mathrm{R})$.

Table 3. Linguistic terms for the comparison of assessment criteria.

\begin{tabular}{lcccc}
\hline Linguistic Terms & Membership Functions & Fuzzy Numbers & Intervals & Abbreviation \\
\hline Absolutely Less & 0 & & $\mathrm{x}=0$ & \\
Important & 1 & $(0,0,0.1,0.2)$ & $0 \leq \mathrm{x} \leq 0.1$ & a1 \\
Much Less & $2-10 \mathrm{x}$ & & $0.1 \leq \mathrm{x} \leq 0.2$ & \\
Important & $10 \mathrm{x}-1$ & $(0.1,0.2,0.2,0.3)$ & $0.1 \leq \mathrm{x} \leq 0.2$ & $\mathrm{a} 2$ \\
& $3-10 \mathrm{x}$ & & $0.2 \leq \mathrm{x} \leq 0.3$ & \\
Less Important & $10 \mathrm{x}-2$ & $(0.2,0.3,0.4,0.5)$ & $0.3 \leq \mathrm{x} \leq 0.4$ & $\mathrm{a} 3$ \\
& 1 & & $0.4 \leq \mathrm{x} \leq 0.5$ & \\
Equally Important & $5-10 \mathrm{x}$ & $(0.4,0.5,0.5,0.6)$ & $0.4 \leq \mathrm{x} \leq 0.5$ & \\
& $10 \mathrm{x}-4$ & & $0.5 \leq \mathrm{x} \leq 0.6$ & \\
& $6-10 \mathrm{x}$ & $0.5 \leq \mathrm{x} \leq 0.6$ & $\mathrm{a}$ \\
More Important & $10 \mathrm{x}-5$ & $(0.5,0.6,0.7,0.8)$ & $0.6 \leq \mathrm{x} \leq 0.7$ & \\
& 1 & & $0.7 \leq \mathrm{x} \leq 0.8$ & \\
& $8-10 \mathrm{x}$ & & $0.7 \leq \mathrm{x} \leq 0.8$ & \\
Much More & $10 \mathrm{x}-7$ & $(0.7,0.8,0.8,0.9)$ & $0.8 \leq \mathrm{x} \leq 0.9$ & \\
Important & $9-10 \mathrm{x}$ & & $0.8 \leq \mathrm{x} \leq 0.9$ & \\
& $10 \mathrm{x}-8$ & & $0.9 \leq \mathrm{x} \leq 1$ & \\
Absolutely More & 1 & $(0.8,0.9,1,1)$ & $\mathrm{x}=1$ & \\
Important & 0 & &
\end{tabular}

Step 5: To express the possibility of selecting a risk factor by experts, a belief level is introduced. The belief level $b_{i j}^{k}(i=1,2, \ldots, t, j=1,2, \ldots, m, k=1,2, \ldots, n)$ belongs to a set of linguistic terms that contain various degrees of preferences required by decision makers. Where ever an expert do not know or cannot give a belief level a '**' sign is used in belief matrix. The linguistic terms for preference belief levels of alternatives are described in Table 4. 
Table 4. Linguistic terms for preference belief levels for alternatives.

\begin{tabular}{|c|c|c|c|c|}
\hline Linguistic Terms & Membership Functions & Fuzzy Numbers & Intervals & Abbreviation \\
\hline \multirow{3}{*}{ Lowest } & 0 & & $x=0$ & \\
\hline & 1 & $(0,0,0.1,0.2)$ & $0 \leq \mathrm{x} \leq 0.1$ & b1 \\
\hline & $2-10 x$ & & $0.1 \leq \mathrm{x} \leq 0.2$ & \\
\hline \multirow{2}{*}{ Very Low } & $10 x-1$ & \multirow{2}{*}{$(0.1,0.2,0.2,0.3)$} & $0.1 \leq \mathrm{x} \leq 0.2$ & \multirow{2}{*}{$\mathrm{b} 2$} \\
\hline & $3-10 x$ & & $0.2 \leq \mathrm{x} \leq 0.3$ & \\
\hline \multirow{3}{*}{ Low } & $10 x-2$ & \multirow{3}{*}{$(0.2,0.3,0.4,0.5)$} & $0.2 \leq \mathrm{x} \leq 0.3$ & \multirow{3}{*}{ b3 } \\
\hline & 1 & & $0.3 \leq \mathrm{x} \leq 0.4$ & \\
\hline & $5-10 x$ & & $0.4 \leq \mathrm{x} \leq 0.5$ & \\
\hline \multirow{2}{*}{ Medium } & $10 \mathrm{x}-4$ & \multirow{2}{*}{$(0.4,0.5,0.5,0.6)$} & $0.4 \leq \mathrm{x} \leq 0.5$ & \multirow{2}{*}{ b4 } \\
\hline & $6-10 x$ & & $0.5 \leq \mathrm{x} \leq 0.6$ & \\
\hline \multirow{3}{*}{ High } & $10 x-5$ & \multirow{3}{*}{$(0.5,0.6,0.7,0.8)$} & $0.5 \leq \mathrm{x} \leq 0.6$ & \multirow{3}{*}{ b5 } \\
\hline & 1 & & $0.6 \leq \mathrm{x} \leq 0.7$ & \\
\hline & $8-10 x$ & & $0.7 \leq \mathrm{x} \leq 0.8$ & \\
\hline \multirow{3}{*}{ Very High } & $10 x-7$ & \multirow{3}{*}{$(0.7,0.8,0.8,0.9)$} & $0.7 \leq \mathrm{x} \leq 0.8$ & \multirow{3}{*}{ b6 } \\
\hline & & & & \\
\hline & $9-10 x$ & & $0.8 \leq \mathrm{x} \leq 0.9$ & \\
\hline \multirow{3}{*}{ Highest } & $10 x-8$ & \multirow{3}{*}{$(0.8,0.9,1,1)$} & $0.8 \leq \mathrm{x} \leq 0.9$ & \multirow{3}{*}{ b7 } \\
\hline & 1 & & $0.9 \leq \mathrm{x} \leq 1$ & \\
\hline & 0 & & $x=1$ & \\
\hline
\end{tabular}

Step 6: By applying the normalized weights resulted from step 4 into belief level matrix $\left(b_{i j}^{k}\right)(k=1,2, \ldots, n)$ and aggregate the results, belief vectors $\bar{b}_{j}^{k}=\tilde{w}_{j_{1}}^{k} *_{j j_{1}}^{k}+\tilde{w}_{j_{2}}^{k} * b_{j_{j}}^{k}+\ldots+\tilde{w}_{j_{s}}^{k} * b_{j j_{s}}^{k}$ where $b_{i j j_{i}}^{k}(i=1,2, \ldots, s)$ is not' $*^{*} *^{\prime}$ are obtained.

Step 7: At this step, normalized weight of decision maker is calculated.

$$
\tilde{v}_{k}^{*}=\frac{\tilde{v}_{k}}{\sum_{i=1}^{n} v_{i_{0}}^{R}} \text { for } k=1,2, \ldots, n .
$$

Step 8: By applying the normalized weight obtained from previous step and belief vectors obtained from step 6 , a weighted normalized fuzzy decision matrix is constructed.

$$
\left(\tilde{r}_{1}, \tilde{r}_{2}, \ldots, \tilde{r}_{m}\right)=\left(\tilde{v}_{1}^{*}, \tilde{v}_{2}^{*}, \ldots, \tilde{v}_{n}^{*}\right)\left(\begin{array}{cccc}
\bar{b}_{1}^{1} & \bar{b}_{2}^{1} & \ldots & \bar{b}_{m}^{1} \\
\bar{b}_{1}^{2} & \bar{b}_{2}^{2} & \ldots & \bar{b}_{m}^{1} \\
\vdots & \vdots & \ddots & \vdots \\
\bar{b}_{1}^{n} & \bar{b}_{2}^{n} & \ldots & \bar{b}_{m}^{n}
\end{array}\right) \text { where } \tilde{r}_{j}=\sum_{k=1}^{n} \tilde{v}_{k}^{*} \bar{b}_{j}^{k}
$$

Step 9: The ideal solution is assessed and the distance between alternatives (risk factor) and the ideal solution will be calculated. Alternative (risk factor) with the least distance is assumed to be the highest priority risk factor selected by group decision. 
Suppose elements in decision matrix defined as $\tilde{r}_{m}=\left(r_{m}^{L}, r_{m}^{M}, r_{m}^{R}\right)$ and the ideal alternative is named $A^{*}=\left[\tilde{x}_{j}^{*}\right]: \tilde{b}_{j}^{*}=\left(x_{j}^{* L}, x_{j}^{* M}, x_{j}^{* R}\right)$. The distance between every alternative in decision matrix and ideal alternative is calculated as follow:

$$
d_{i}=d_{\left(\tilde{r}_{m}, A^{*}\right)}=\sqrt{\frac{1}{3} \sum_{j=1}^{m}\left[\left(r_{m}^{L}-x_{j}^{* L}\right)^{2}+\left(r_{m}^{M}-x_{j}^{* M}\right)^{2}+\left(r_{m}^{R}-x_{j}^{* R}\right)^{2}\right]}
$$

Assume that decision matrix is a set of pairs $\left(r_{K}, r_{L}\right)$ that $r_{K}$ is preferred to $r_{L}$. This implies that risk factor $\mathrm{K}$ has more effect on project objectives than risk factor $\mathrm{L}$ and distance $\left(d_{i}\right)$ between risk factor $\mathrm{K}$ to ideal set of alternatives (risk items) is less than risk factor $\mathrm{L}\left(d_{L} \geq d_{K}\right)$. As we stated before, experts may have no or incomplete information about assessment criteria; so we the human errors in prediction should be considered. This error $\left(d^{-}\right)$and the amount of incredibility (error) in pair-wise comparison of alternatives $(B)$ to find the negative ideal solution is defined as bellow:

$$
\begin{gathered}
d_{K, L}^{-}= \begin{cases}d_{K}-d_{L} & d_{K}>d_{L} \\
0 & d_{K} \leq d_{L}\end{cases} \\
d_{K, L}^{-}=\max \left\{0, d_{K}-d_{L}\right\} \\
B=\sum_{(K, L) \in \tilde{r}_{m}} d_{K, L}^{-}
\end{gathered}
$$

To obtain the positive ideal solution, a new value called credibility judgment degree is defined between two risk factors $\mathrm{K}$ and $\mathrm{L}$.

$$
\begin{gathered}
d_{K, L}^{+}= \begin{cases}d_{L}-d_{K} & d_{L}>d_{K} \\
0 & d_{L} \leq d_{K}\end{cases} \\
d_{K, L}^{+}=\max \left\{0, d_{L}-d_{K}\right\} \\
G=\sum_{(K, L) \in \tilde{r}_{m}} d_{K, L}^{+}
\end{gathered}
$$

To obtain the final ideal solution, credibility degree should be maximized while incredibility (error) degree should be minimized. Amount of this difference $(b)$ and $P$ should be defined by decision makers $(G-B \geq b)$. The membership function of this ideal solution is as follow:

$$
\mu_{(G-B)}=\frac{(G-B)-(b-P)}{P}=\frac{\sum_{\left(K, L \in \tilde{r}_{m}\right)}\left(d_{L}-d_{K}\right)-(b-P)}{P}
$$

In the field of risk selection in construction projects, $b$ can be the defined as the least effect of a risk item in project objective and amount of $P$ can be described as the highest effect of a risk item. The membership function of $G-B$ is shown on Fig. 4. 


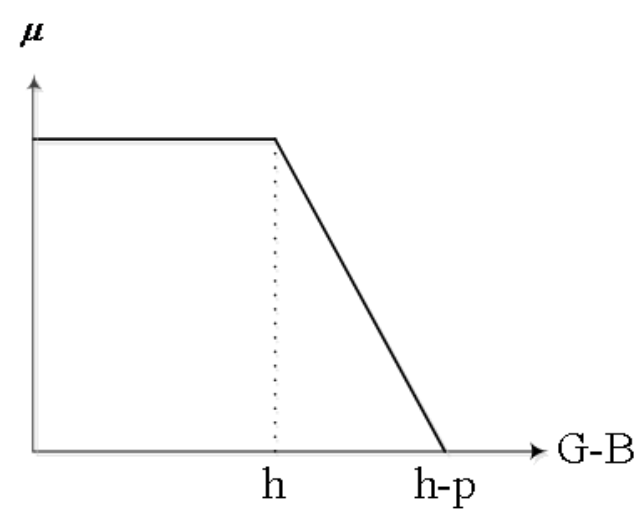

Fig. 4. Membership function of G-B.

The distance $\left(d_{i}\right)$ of alternatives (risk factors) with ideal solution (G-B) is calculated. The risk factor with the least distance is selected as the highest priority factor to be considered and other factors will be ranked in ascending order.

\section{Comparing the Proposed Fuzzy MCDM Model with Fuzzy AHP}

In this section, a comparison between proposed fuzzy MCDM model and different fuzzy AHP approaches is presented. This part of the paper is followed by definition of AHP, Fuzzy AHP, their shortcomings and benefits of our model comparing to fuzzy AHP.

\subsection{AHP}

The AHP is a popular decision making technique that has proven easy to understand and plausible for prioritizing alternatives among multi-criteria and multi-attributes (Saaty [15], Kim and Whang [16], Cheng [17], Badri [18], Lee, Kwak [19], Harbi [20]). The use of AHP need not involve troublesome mathematics but decomposition, pair-wise comparison and priority vector creation (Zeng et.al. [14]). Because AHP does not take into account the uncertainty associated with the mapping of one's judgment to a number and also the subjective judgments, selection, and preference of decision makers exert a strong influence in the AHP. AHP method can only deal with definite scales in reality (Zeng et.al. [14]) while Construction problems are complicated usually involving massive uncertainties and subjectivities. In a typical AHP method, experts have to give a definite number within a 1-9 scale to the pair-wise comparison so that the priority vector can be computed. However factor comparisons often involve certain amount of uncertainty and subjectivity because sometimes, experts cannot compare two factors due to the lack of adequate information. In this case, a typical AHP method has to be discarded due to the existence of fuzzy or incomplete comparisons. In this case a fuzzy AHP approach may be applied.

\subsection{Fuzzy AHP}

A Fuzzy AHP is an important extension of the typical AHP method which was first introduced by Laarhoven and Pedrycz [21]. One of the drawbacks of fuzzy AHP method is the complicated fuzzy operation and the lack of proven techniques to address fuzzy consistency and fuzzy priority vector.

\subsection{Comparison of Proposed Fuzzy MCDM Model with Fuzzy AHP}

To discover the characteristics and advantages of proposed fuzzy MCDM model and fuzzy AHP a comparison between Main characteristics, advantages and disadvantages of different fuzzy AHP approaches (Tuysuz, Kahraman [22]) is implemented in Table 5.

Table 5. The comparison of different fuzzy AHP methods with proposed fuzzy MCDM 


\begin{tabular}{|c|c|c|}
\hline Source & $\begin{array}{l}\text { The main characteristics of } \\
\text { method }\end{array}$ & $\begin{array}{l}\text { Advantages }(+) \text { and } \\
\text { Disadvantages }(-)\end{array}$ \\
\hline Laarhoven,, Pedrycz [21] & $\begin{array}{l}\text { - Direct extension of Saaty's } \\
\text { AHP method with triangular } \\
\text { fuzzy numbers } \\
\text { - Lootsma's logarithmic least } \\
\text { square method is used to derive } \\
\text { fuzzy weights and fuzzy } \\
\text { performance scores }\end{array}$ & $\begin{array}{l}(+) \text { The opinions of multiple } \\
\text { decision makers can be modeled } \\
\text { in the reciprocal matrix. } \\
(-) \text { There is not always a solution } \\
\text { to the linear equations. } \\
(-) \text { The computational requirement } \\
\text { is tremendous, even for a small } \\
\text { problem. } \\
\text { (-) It allows only triangular fuzzy } \\
\text { numbers to be used. }\end{array}$ \\
\hline Buckley [23] & $\begin{array}{l}\text { - Extension of Saaty's AHP } \\
\text { method with trapezoidal fuzzy } \\
\text { numbers } \\
\text { - Uses the geometric mean } \\
\text { method to derive fuzzy weights } \\
\text { and performance scores }\end{array}$ & $\begin{array}{l}\text { (+) It is easy to extend to the } \\
\text { fuzzy case. } \\
(+) \text { It guarantees a unique } \\
\text { solution to the reciprocal } \\
\text { comparison matrix. } \\
(-) \text { The computational } \\
\text { requirement is tremendous. }\end{array}$ \\
\hline $\begin{array}{l}\text { Boender, Grann, Lootsma } \\
\text { [24] }\end{array}$ & $\begin{array}{l}\text { - Modifies van Laarhoven and } \\
\text { Pedrycz's method } \\
\text { - Presents a more robust } \\
\text { approach to the normalization } \\
\text { of the local priorities }\end{array}$ & $\begin{array}{l}(+) \text { The opinions of multiple } \\
\text { decision makers can be modeled. } \\
(-) \text { The computational requirement } \\
\text { is tremendous. }\end{array}$ \\
\hline Chang [25] & $\begin{array}{l}\text { - Synthetical degree values low. } \\
\text { - Layer simple sequencing } \\
\text { - Composite total sequencing }\end{array}$ & $\begin{array}{l}(+) \text { The computational } \\
\text { requirement is relatively low. } \\
\text { (+) It follows the steps of crisp } \\
\text { AHP. It does not involve } \\
\text { additional operations. } \\
\text { (-) It allows only triangular fuzzy } \\
\text { numbers to be used. }\end{array}$ \\
\hline Cheng [17] & $\begin{array}{l}\text { - Builds fuzzy standards } \\
\text { - Represents performance scores } \\
\text { by membership functions both } \\
\text { probability and possibility } \\
\text { measures. } \\
\text { - Uses entropy concepts to } \\
\text { calculate aggregate weights }\end{array}$ & $\begin{array}{l}(+) \text { The computational } \\
\text { requirement is not tremendous. } \\
(-) \text { Entropy is used when } \\
\text { probability distribution is known. } \\
\text { The method is based on both } \\
\text { probability and possibility } \\
\text { measures. }\end{array}$ \\
\hline Proposed Fuzzy MCDM & $\begin{array}{l}\text { - Extension of rational model } \\
\text { - Consensus rule based } \\
\text { - Self optimization } \\
\text { - Characterized for risk analysis } \\
\text { - Uses Euclidean distance to find } \\
\text { optimal solution } \\
\text { - Pair-wise inconsistency } \\
\text { correction }\end{array}$ & $\begin{array}{l}\text { (+) Uncertainty factors in group } \\
\text { decision making are assessed by } \\
\text { applying fuzzy logic } \\
(+) \text { Final solution is prioritized } \\
(+) \text { Different fuzzy numbers and } \\
\text { membership functions can be } \\
\text { applied } \\
(+) \text { Experts can have inconsistent } \\
\text { evaluation } \\
\text { (+) Experts decision weight is } \\
\text { efficiently applied to model } \\
(-) \text { The computation requirement } \\
\text { is relatively high }\end{array}$ \\
\hline
\end{tabular}




\section{Case Study}

To illustrate the application of proposed fuzzy multi-criteria group decision making model in construction risk selection, we applied this model to a concrete forming project as a case study. In concrete forming projects, scheduling the concrete trucks and availability of forms are very important and in close relationship. Safety of crew especially in high rise structures and severity of weather are other affecting factors in success of a concrete forming project. By applying proposed fuzzy MCDM model to this case study it is expected that scheduling and availability of forms be ranked as highest priority with close relationship.

Suppose a group of experts to identify inherent risk in a concrete forming project consist of three experts P1, P2 and P3. To avoid complexity of manual computations, it is assumed that experts have same influence weights. Their weights, preference for risk factor selection and judgments for proposed assessment criteria are described in Tables 1,3 and 4 . The risk selection process by using proposed method is described as follow:

Stage 1: Alternatives, assessment criteria and influence weights generation

Step 1: to initiate the selection process, involved risks in project should be classified. Each expert proposes one or more risk factor for project risk selection. Final alternative risk $S$ is determined by merging similar risk factors.

$$
S=\left\{S_{1}, S_{2}, S_{3}, S_{4}\right\}
$$

S1: Safety, S2: Scheduling, S3: Unavailability of resources, S4: Weather

Step 2: The experts should assess these risk factors with regard to magnitude and effect on project objectives by proposing an assessment criteria. In this case study we put emphasis on project duration and assess risk factors based on their impact on project duration. By merging overlapped criteria, five assessment criteria C1, C2, C3, C4 and C5 are obtained.

C1: Effect of new safety plans on project duration

C2: The impact of changing operations' scheduling on project delivery

C3: Change operations from non-critical to critical due to unavailability of resources

C4: Consequence of undesired weather condition on project delays with regard to project location.

C5: Impact of risk factor on costumer

Step 3: to avoid the complexity, we assume that all experts have same influence weights as 'normal'.

Stage 2: Individual preferences generation

Step 4: Five assessment criteria obtained from previous step are being judged by using pair-wise comparison. At this step, every expert should present his individual judgment for assessment criteria. Resulted pair-wise comparison matrices are calculated as follow:

$$
E^{1}=E^{2}=E^{3}=\left(\begin{array}{ccccc}
E I & E I & * & * & E I \\
E I & E I & * & E I & * \\
* & * & E I & * & * \\
* & E I & * & E I & E I \\
E I & * & * & E I & E I
\end{array}\right)=\left(\begin{array}{ccccc}
a_{4} & a_{4} & * & * & a_{4} \\
a_{4} & a_{4} & * & a_{4} & * \\
* & * & a_{4} & * & * \\
* & a_{4} & * & a_{4} & a_{4} \\
a_{4} & * & * & a_{4} & a_{4}
\end{array}\right)
$$

To correct the inconsistency of each pair-wise comparison matrix, the positive-transitive, De-In and InDe uncertainty rules are applied. Finalized pair-wise comparison matrices to express the possibility of selecting a risk factor, under certain criteria is as follow: 


$$
E^{1}=E^{2}=E^{3}=\left(\begin{array}{ccccc}
E I & E I & * & E I & E I \\
E I & E I & * & E I & * \\
* & * & E I & * & * \\
E I & E I & * & E I & E I \\
E I & * & * & E I & E I
\end{array}\right)=\left(\begin{array}{ccccc}
a_{4} & a_{4} & * & a_{4} & a_{4} \\
a_{4} & a_{4} & * & a_{4} & * \\
* & * & a_{4} & * & * \\
a_{4} & a_{4} & * & a_{4} & a_{4} \\
a_{4} & * & * & a_{4} & a_{4}
\end{array}\right)
$$

Normalized pair-wise comparison matrix and consistent weight for every assessment criteria are calculated by computing the geometric mean of every row.

$$
\begin{gathered}
\left(\begin{array}{l}
w_{1}^{1} \\
w_{2}^{1} \\
w_{3}^{1} \\
w_{4}^{1} \\
w_{5}^{1}
\end{array}\right)=\left(\begin{array}{l}
w_{1}^{2} \\
w_{2}^{2} \\
w_{3}^{2} \\
w_{4}^{2} \\
w_{5}^{2}
\end{array}\right)=\left(\begin{array}{l}
w_{1}^{3} \\
w_{2}^{3} \\
w_{3}^{3} \\
w_{4}^{3} \\
w_{5}^{3}
\end{array}\right)=\left(\begin{array}{l}
\sqrt[4]{a_{4}^{4}} \\
\sqrt[3]{a_{4}^{3}} \\
a_{4} \\
\sqrt[4]{a_{4}^{4}} \\
\sqrt[3]{a_{4}^{3}}
\end{array}\right)=\left(\begin{array}{l}
a_{4} \\
a_{4} \\
a_{4} \\
a_{4} \\
a_{4}
\end{array}\right)=\left(\begin{array}{l}
{[10 x-4,6-10 x]} \\
{[10 x-4,6-10 x]} \\
{[10 x-4,6-10 x]} \\
{[10 x-4,6-10 x]} \\
{[10 x-4,6-10 x]}
\end{array}\right) \\
\sum_{i=1}^{5} w_{i_{0}}^{1^{R}}=\sum_{i=1}^{5} w_{i_{0}}^{2^{R}}=\sum_{i=1}^{5} w_{i_{0}}^{3^{R}}=3 \\
\left(\begin{array}{l}
\tilde{w}_{1}^{1} \\
\tilde{w}_{2}^{1} \\
\tilde{w}_{3}^{1} \\
\tilde{w}_{4}^{1} \\
\tilde{w}_{5}^{1}
\end{array}\right)=\left(\begin{array}{l}
\tilde{w}_{1}^{2} \\
\tilde{w}_{2}^{2} \\
\tilde{w}_{3}^{2} \\
\tilde{w}_{4}^{2} \\
\tilde{w}_{5}^{2}
\end{array}\right)=\left(\begin{array}{l}
\tilde{w}_{1}^{3} \\
\tilde{w}_{2}^{3} \\
\tilde{w}_{3}^{3} \\
\tilde{w}_{4}^{3} \\
\tilde{w}_{5}^{3}
\end{array}\right)=\frac{1}{3}\left(\begin{array}{l}
a_{4} \\
a_{4} \\
a_{4} \\
a_{4} \\
a_{4}
\end{array}\right)
\end{gathered}
$$

Step 5: To express the possibility of selecting a risk factor $\left(S_{i}\right)$ under criterion $\left(C_{j}\right)$, three belief level matrices are obtained by group members:

$$
\begin{aligned}
& \left(\begin{array}{lllll}
b_{11}^{1} & b_{12}^{1} & b_{13}^{1} & b_{14}^{1} & b_{15}^{1} \\
b_{21}^{1} & b_{22}^{1} & b_{23}^{1} & b_{24}^{1} & b_{25}^{1} \\
b_{31}^{1} & b_{32}^{1} & b_{33}^{1} & b_{34}^{1} & b_{35}^{1} \\
b_{41}^{1} & b_{42}^{1} & b_{43}^{1} & b_{44}^{1} & b_{45}^{1}
\end{array}\right)=\left(\begin{array}{ccccc}
M & V L & * * & * * & * * \\
V H & M & * * & * * & * * \\
* * & * * & M & V L & * * \\
* * & V L & * * & * * & M
\end{array}\right)=\left(\begin{array}{lllll}
b_{4} & b_{1} & * * & * * & * * \\
b_{7} & b_{4} & * * & * * & * * \\
* * & * * & b_{4} & b_{1} & * * \\
* * & b_{1} & * * & * * & b_{4}
\end{array}\right), \\
& \left(\begin{array}{llllll}
b_{11}^{2} & b_{12}^{2} & b_{13}^{2} & b_{14}^{2} & b_{15}^{2} \\
b_{21}^{2} & b_{22}^{2} & b_{23}^{2} & b_{24}^{2} & b_{25}^{2} \\
b_{31}^{2} & b_{32}^{2} & b_{33}^{2} & b_{34}^{2} & b_{35}^{2} \\
b_{41}^{2} & b_{42}^{2} & b_{43}^{2} & b_{44}^{2} & b_{45}^{2}
\end{array}\right)=\left(\begin{array}{ccccc}
M & V L & * * & * * & * * \\
V H & * * & M & * * & * * \\
* * & * * & V L & M & * * \\
* * & M & * * & * * & V L
\end{array}\right)=\left(\begin{array}{lllll}
b_{4} & b_{1} & * * & * * & * * \\
b_{7} & * * & b_{4} & * * & * * \\
* * & * * & b_{1} & b_{4} & * * \\
* * & b_{4} & * * & * * & b_{1}
\end{array}\right), \\
& \left(\begin{array}{llllll}
b_{11}^{3} & b_{12}^{3} & b_{13}^{3} & b_{14}^{3} & b_{15}^{3} \\
b_{21}^{3} & b_{22}^{3} & b_{23}^{3} & b_{24}^{3} & b_{25}^{3} \\
b_{31}^{3} & b_{32}^{3} & b_{33}^{3} & b_{34}^{3} & b_{35}^{3} \\
b_{41}^{3} & b_{42}^{3} & b_{43}^{3} & b_{44}^{3} & b_{45}^{3}
\end{array}\right)=\left(\begin{array}{ccccc}
V L & M & * * & * * & * * \\
M & * * & V H & * * & * * \\
* * & * * & M & V L & * * \\
* * & M & * * & * * & V L
\end{array}\right)=\left(\begin{array}{lllll}
b_{1} & b_{4} & * * & * * & * * \\
b_{4} & * * & b_{7} & * * & * * \\
* * & * * & b_{4} & b_{1} & * * \\
* * & b_{4} & * * & * * & b_{1}
\end{array}\right) .
\end{aligned}
$$

Step 6: By applying the results obtained from step 4 to belief level matrix, three belief vectors are obtained as follow: 


$$
\begin{aligned}
& \bar{b}_{1}^{1}=\frac{1}{3}\left(a_{4}^{2}+a_{4} a_{1}\right), \bar{b}_{2}^{1}=\frac{1}{3}\left(a_{4}^{2}+a_{4} a_{7}\right), \bar{b}_{3}^{1}=\frac{1}{3}\left(a_{4}^{2}+a_{4} a_{1}\right), \bar{b}_{4}^{1}=\frac{1}{3}\left(a_{4}^{2}+a_{4} a_{1}\right), \\
& \bar{b}_{1}^{2}=\frac{1}{3}\left(a_{4}^{2}+a_{4} a_{1}\right), \bar{b}_{2}^{2}=\frac{1}{3}\left(a_{4}^{2}+a_{4} a_{1}\right), \bar{b}_{3}^{2}=\frac{1}{3}\left(a_{4}^{2}+a_{4} a_{1}\right), \bar{b}_{4}^{2}=\frac{1}{3}\left(a_{4}^{2}+a_{4} a_{1}\right), \\
& \bar{b}_{1}^{3}=\frac{1}{3}\left(a_{4}^{2}+a_{4} a_{1}\right), \bar{b}_{2}^{3}=\frac{1}{3}\left(a_{4}^{2}+a_{4} a_{7}\right), \bar{b}_{3}^{3}=\frac{1}{3}\left(a_{4}^{2}+a_{4} a_{1}\right), \bar{b}_{4}^{3}=\frac{1}{3}\left(a_{4}^{2}+a_{4} a_{1}\right) .
\end{aligned}
$$

Stage 3: Group aggregation

Step 7: The normalized weight of decision makers denoted as follow:

$$
\begin{aligned}
& v_{1}=v_{2}=v_{3}=c_{1} \\
& \sum_{i=1}^{3} v_{i_{0}}^{R}=1.2 \\
& v_{1}^{*}=v_{2}^{*}=v_{3}^{*}=\frac{1}{1.2} a_{4}
\end{aligned}
$$

Step 8: By applying obtained results from steps 6 and 7, weighted and normalized fuzzy decision vector is constructed:

$$
\begin{aligned}
& \tilde{r}_{1}=v_{1}^{*} \bar{b}_{1}^{1}+v_{2}^{*} \bar{b}_{1}^{2}+v_{3}^{*} \bar{b}_{1}^{3}=\frac{1}{1.2} a_{4}^{2}\left(a_{4}+a_{1}\right)=\frac{1}{1.2}\left[(10 x-4)^{2},(6-10 x)^{2}\right][(10 x-4),(8-20 x)], \\
& \tilde{r}_{2}=v_{1}^{*} \bar{b}_{2}^{1}+v_{2}^{*} \bar{b}_{2}^{2}+v_{3}^{*} \bar{b}_{2}^{3}=\frac{1}{1.2} a_{4}^{2}\left(a_{4}+a_{7}\right)=\frac{1}{1.2}\left[(10 x-4)^{2},(6-10 x)^{2}\right][(20 x-12),(6-10 x)], \\
& \tilde{r}_{3}=v_{1}^{*} \bar{b}_{3}^{1}+v_{2}^{*} \bar{b}_{3}^{2}+v_{3}^{*} \bar{b}_{3}^{3}=\frac{1}{1.2} a_{4}^{2}\left(a_{4}+a_{1}\right)=\frac{1}{1.2}\left[(10 x-4)^{2},(6-10 x)^{2}\right][(10 x-4),(8-20 x)], \\
& \tilde{r}_{4}=v_{1}^{*} \bar{b}_{4}^{1}+v_{2}^{*} \bar{b}_{4}^{2}+v_{3}^{*} \bar{b}_{4}^{3}=\frac{1}{1.2} a_{4}^{2}\left(a_{4}+a_{1}\right)=\frac{1}{1.2}\left[(10 x-4)^{2},(6-10 x)^{2}\right][(10 x-4),(8-20 x)] .
\end{aligned}
$$

Step 9: To reach the ideal solution, it is assumed that the ideal risk factor has minimum 0.25 and maximum 0.75 effect on project duration. The distances between obtained decision vector item for each risk factor and ideal risk factor are depicted below:

$$
\begin{aligned}
& d_{S_{1}}=0.1536 \quad \text { (Safety) } \\
& d_{S_{2}}=0.0695 \quad \text { (Scheduling) } \\
& d_{S_{3}}=0.0725 \text { (Unavailability of resources) } \\
& d_{S_{4}}=0.1536 \quad \text { (Weather) }
\end{aligned}
$$

\subsection{Discussion of Results}

By considering relative Euclidean distance, it is concluded that 'scheduling' risk factor has the most effect on project duration and 'unavailability of resources', 'safety' and 'weather' are on next order. Another conclusion that can be obtained from these results is the criticality and dependency of "Scheduling" and "Unavailability of resources". As can be seen, "Unavailability of resources" has a closer distance to the most critical risk factor than "Safety" and "Weather" which shows a dependency between "Unavailability of resources" and "Scheduling". Due to the dependency of these two risk factors, improving them should be done simultaneously. Otherwise improving one risk factor may lead to criticality of other.

Considering the result of this case study, project manager or decision maker should consider factors and operations that may cause "scheduling" to be critical on project objective. For instance, he may re- 
arrange the float times or make revisions on critical paths. Also he may take into consideration the share activities that overlap the "Unavailability of resources".

\subsection{Result Comparison with Fuzzy AHP}

To discuss the difference between the proposed fuzzy MCDM and the fuzzy AHP, same case study has been implemented using Chang (1996) fuzzy AHP approach. Because of the advantages Chang's extent analysis on fuzzy AHP are relatively superior to the others due to the reasons mentioned in Table 5, this method will be used in project risk evaluation (Tuysuz, Kahraman 2006). Because Chang`s approach allows only triangular fuzzy numbers, related non-triangular fuzzy numbers in case study, has been converted to triangular fuzzy numbers. After relatively high and time consuming computations, obtained results are as follow:

$$
\begin{aligned}
& \text { Risk Factor } 1=\text { Scheduling } \\
& \text { Risk Factor } 2=\text { Unavailability of resources } \\
& \text { Risk Factor } 3=\text { Safety } \\
& \text { Risk Factor } 4=\text { Weather }
\end{aligned}
$$

As concluded from this comparison, the priority rank of risk factors is same with proposed fuzzy MCDM method but the computations in utilized fuzzy AHP method is relatively high and limitation in applying other membership functions and fuzzy numbers rather than triangular fuzzy numbers, make it impractical in the field of construction risk assessment. Also there is no rational comparison between prioritized risk factors and as the result risk mitigation strategy cannot effectively be added to risk management process.

\section{Conclusion}

In this paper we introduced a comprehensive hierarchical risk classification for construction projects through an extensive literature review and experiences in different projects. The main matter in an effective risk management plan is managing the most effective risks which have the maximum effect on project objectives. Due to lack of information and limited time, all the risk factors in a project cannot be considered for assessment. So a comprehensive risk selection mechanism should be developed to prioritize the inherent risks. In this study we developed this mechanism through a fuzzy multi criteria decision making model which is based on group decision making. Presented method has both advantages of a self optimization and no limitation for experts. Case studies have shown reasonable results by utilizing this method. As shown in case study results, not only prioritized risk factors can be selected by proposed method but also the interdependency of risk factors can be identified by comparing the relative distance of risk factors to each other. This option gives the decision makers a guide map of managing relative risk factors otherwise improving one factor will make others be critical. Several methods presented to solve above MCDM problems. Some of them are based on ideal alternative in the decision maker's opinion such as TOPSIS and ELECTRE. In the cases where ideal alternative and weight of criteria are not available for decision maker, aforesaid methods are not applicable. One of the shortcomings of this method is the tedious calculations of matrices. This can be improved by programming the calculations using spreadsheet or other programming solutions. Also in this study to simplify the fuzzy sets, we utilized the triangular fuzzy membership functions that may not be suitable for complex systems. Further studies can be conducted in developing the programming solution for this model and utilizing other membership functions for complex problems.

\section{References}

[1] Project Management Institute Standards Committee, "A guide to the project management body of knowledge," Project Management Institute, 2008.

[2] D. F. Cooper, and C. B. Champan, Risk Analysis for Large Project, Wiley, Chichester, 1987. 
[3] A. Klemetti, "Risk management in construction project networks," Report 2006/ 2, Finland: Laboratory of Industrial Management, Helsinki University of Technology, 2006.

[4] L. Zhou, A. Vasconcelos, and M. Numes, Information Management and Computer Security, vol. 16, pp. 166, 2008.

[5] J. H. Perry, and R. W. Hayes, "Risk and its management in construction projects," Proceedings of the Institution of Civil Engineering, Part I, vol. 78, pp. 499-521, 1985.

[6] O. A. Abdou, "Managing construction risks," Journal of Architectural Engineering, vol. 2(1), pp. 3-10, 1996.

[7] L. Y. Shen, G. W. C. Wu, and C. S. K. Ng, "Risk assessment for construction joint ventures in China," Journal of Construction Engineering and Management, vol. 127(1), pp. 76-81, 2001.

[8] J. H. M. Tah, and V. Carr, "A proposal for construction project risk assessment using fuzzy logic," Construction Management and Economics, vol. 18, pp. 491-500, 2000.

[9] R. J. Chapman, "The controlling influences on effective risk identification and assessment for construction design management," International Journal of Project Management, vol. 19, pp. 147-160, 2001.

[10] L. Y. Shen, "Project risk management in Hong Kong," International Journal of Project Management, vol. 15(2), pp. 101-105, 1997.

[11] H. Chen, G. Hao, S. W. Poon, and F. F. Ng, "Cost risk management in West Rail project of Hong Kong," AACE International Transactions, 2004.

[12] S. A. Assaf, and S. Al-Hejji, "Causes of delay in large construction projects," International Journal of Project Management, vol. 24(4), pp. 349-357, 2006.

[13] I. Dikmen, M. Birgonul, and S. Han, "Using fuzzy risk assessment to rate cost overrun risk in international construction projects," International Journal of Project Management, vol. 25, pp. 494-505, 2007.

[14] J. Zeng, M. An, and N. J. Smith, "Application of a fuzzy based decision making methodology to construction project risk assessment," International Journal of Project Management, vol. 25, pp. 589-600, 2007

[15] T. L. Saaty, Multicriteria Decision Making: The Analytic Hierarchy Process, Pittsburgh (US): RWS Publications, 1990.

[16] S. B. Kim, and K. S. Whang, "Forecasting the capabilities of Korean civil aircraft industry," Omega, vol. 21(1), pp. 91-98, 1993.

[17] C. H. Cheng "Evaluating naval tactical missile systems by fuzzy AHP based on the grade value of membership function," European Journal of Operational Research, vol. 96, pp. 343-50, 1996.

[18] M. Badri "Combining the AHP and GP for global facility location-allocation problem," International Journal of Production Economics, vol. 62(3), pp. 237-248, 1999.

[19] C. W. Lee, and N. K. Kwak, "Information resource planning for a health-care system using an AHPbased goal programming method," Journal of the Operational Research Society, vol. 50, pp. 1191-1198, 1999.

[20] K. M. A. Harbi, "Application of AHP in project management," International Journal of Project Management, vol. 19(4), pp. 19-27, 2001.

[21] P. J. M. Laarhoven, and W. Pedrycz, "A fuzzy extension of Saaty's priority theory," Fuz:y Sets and Systems, vol. 11, pp. 229-241, 1983.

[22] F. Tuysuz, and C. Kahraman, "Project risk evaluation using a fuzzy analytic hierarchy process: An application to information technology projects," International Journal of Intelligent Systems, vol. 21, pp/ 559-584, 2006.

[23] J. J. Buckley, "Fuzzy hierarchical analysis," Fuz:y Sets and Systems, vol. 17, pp. 233-247, 1985.

[24] C. G. E. Boender, J. G. de Grann, and F. A. Lootsma, "Multicriteria decision analysis with fuzzy pairwise comparison," Fuzzy Set and Systems, vol. 29, pp. 133-143, 1989.

[25] D.-Y. Chang, "Applications of the extent analysis method on fuzzy AHP," European Journal of Operational Research, vol. 95, pp. 649-655, 1996. 
